\title{
Mental models and social media personas: A case of amateur palaeontologists
}

\section{Lisa Lundgren}

College of Education School of Teaching and Learning,

University of Florida,

Gainesville, United States

Email: lisa.lundgren@ufl.edu

\section{Kent J. Crippen*}

College of Education School of Teaching and Learning,

University of Florida,

Gainesville, United States

Email: kcrippen@coe.ufl.edu

*Corresponding author

\section{Eleanor E. Gardner}

Biodiversity Institute and Natural History Museum,

University of Kansas,

Lawrence, United States

Email: Eleanor.gardner@ku.edu

\section{Victor J. Perez}

Department of Geological Sciences,

Florida Museum of Natural History,

Gainesville, United States

Email: victorjperez@ufl.edu

\section{Ronny Maik Leder}

Natural History Museum City of Leipzeig,

Leipzeig, Germany

leder.ronnymaik@googlemail.com

\begin{abstract}
This study explores the practice of social palaeontology - an inclusive form of collaborative inquiry of the natural world through the collection, preparation, curation, and study of fossils which is enacted across digital habitats. The purpose was to a) examine conceptualizations of social palaeontology via expressed mental models for a group of amateur palaeontologists and b) use the unified media-user typology (MUT) to explore relationships between these models and participants' social media personas. Data collection occurred using a survey, mental model task, and a follow-up interview. Findings reveal that participants were most likely to employ sequential mental models for describing social palaeontology and that as a person's social media persona increases in expertise, the expertise is not conveyed in the descriptions of social media
\end{abstract}


conventions. The results bolster the capacity to design community-centered social spaces and inform the collective understanding of contemporary science learning and the utility of MUT as a predictive tool.

Keywords: palaeontology, user typology, informal education, mental models, social media personas

Reference to this paper should be made as follows: Lundgren, L., Crippen, K. J., Gardner, E. E., Perez, V. J., and Leder, R. M. (2018) 'Mental models and social media personas: A case of amateur palaeontologists', Int. J. Social Media and Interactive Learning Environments,

Biographical notes: Lisa Lundgren is a Graduate Research Assistant studying Science Education at the University of Florida. Her research employs a designbased research perspective to develop theoretical insights related to the practice of learning. She specifically focuses on the design and development of social media for informal science learning environments.

Kent Crippen is an Associate Professor of STEM Education at the University of Florida. His work focuses on theoretically grounded design for the dual purpose of addressing contemporary, in situ learning problems while generating theoretical insight related to the process of learning and the relationships among people, tools, and context.

Eleanor Gardner is the Outreach \& Engagement Coordinator at the University of Kansas Natural History Museum. She holds degrees in biology and geology, having specialized in palaeontology, and is interested in how people of all ages understand and engage with scientific concepts.

Victor Perez is a PhD student at the University of Florida, pursuing a degree in Geology with minors in Biology and Science Education. His primary research interest involves interpreting the fossil record of sharks to reconstruct past environments. This research often lends itself to collaborating with amateur paleontologists.

Ronny Maik Leder is a palaeobiologist and the Director General of the Natural History Museum of the City of Leipzig. His research focuses mainly on morphometric analysis of fossil shark teeth, fossil fish faunas, and marine biota in general but also on terrestrial fossil faunas and tertiary plant associations.

\section{Introduction}

Palaeontology, the study of ancient life, is often promoted as a gateway into STEM (Science, Technology, Engineering, and Mathematics): dinosaur skeletons are featured prominently in museum exhibits, students learn about fossils at a young age, and diverse and accessible opportunities are provided for participating in the science. Case in point, the Chewing on Change curriculum for elementary students is based upon morphological changes in fossil horse teeth and the study of museum collection-quality fossils (Bokor et al., 2016; Moran et al., 2015). In addition to classroom pursuits, varied forms of informal participation and contribution to palaeontology include the efforts of museums and the public. Those who participate in and contribute to palaeontology without being paid to do 
so are referred to as avocational or amateur palaeontologists; they form affinity groups, as clubs or societies, and often partake in the full spectrum of palaeontological inquiry, including fossil collection, identification, preparation, curation, and digitization (Crippen et al., 2015). Amateur palaeontologists represent a particularly relevant yet understudied area of research concerning people who participate in interest-driven, scientific hobbies, meaning that the individuals involved are self-motivated for participation (Azevedo, 2013).

Current research recognizes that science learning occurs throughout a person's lifetime, across time and space in both formal and informal contexts (Bell et al., 2009; Falk and Dierking, 2013). This includes online spaces, such as community forums and social media, as well as face-to-face, formalized environments such as schools or workshops. Although formalized schooling is the primary venue in the first few decades of life, the majority of science learning occurs in informal environments such as museums, aquaria, online forums, or events such as fossil club meetings (Falk and Storkdieck, 2010).

For science domains that are based upon observations of natural phenomena, like palaeontology or ornithology, learners have the opportunity for first-person participation, potentially making a contribution to science while supporting their own development (Jones et al., 2016; Miller-Rushing et al., 2012). Such participatory learning is supported by social interactions with other participants who are engaged in the same endeavour (Bonney et al., 2015). Online spaces can augment participatory learning by supporting the necessary social interactions and allowing learners to illustrate their practice and demonstrate their expertise (Racaniello, 2010). Wenger and colleagues (2009) define these online spaces as digital habitats and though they have been shown to emerge naturally, the goal of this study is to understand how to design them in order to further support the science (Bismack et al., 2015). In an effort towards achieving this goal, the potential connection between a group of amateurs' understanding of social palaeontology - a computersupported collaborative form of science involving the collection, preparation, curation, and study of fossils (Crippen et al., 2016) and the use of social media is explored. In doing so, the theory of media use as it relates to science learning in informal spaces is advanced.

The purpose of this study was to a) examine the conceptualizations of social palaeontology via expressed mental models for a group of amateurs and b) use Brandtzaeg's (2010) unified media-user typology (MUT) to explore any relationship between these models and the participant's social media persona. Grounded in a metaanalysis, the MUT is proposed as a general user classification system that can transcend culture and provide explanatory power regarding media use as a proxy for expertise and/or digital literacy. However, this capacity for prediction has yet to be tested. Therefore, the following research questions guided the study:

1. What mental models of social palaeontology do amateur palaeontologists possess?

2. In what ways are amateur palaeontologists' mental models related to their social media personas?

The focus on amateur palaeontologists' mental models and the MUT's potential as a predictive classification scheme stems from the effort to design an inclusive digital habitat. In addition to building capacity for achieving design goals, the results inform the collective understanding of contemporary science learning: that which recognizes the value of situated practice, is technology-mediated, occurs outside of formal schooling, and involves people from across a continuum of expertise. 


\section{Theoretical Framework}

\subsection{Media User Typologies}

Individuals create diverse but potentially predictable patterns as they use social media (Zhao et al., 2016). Learning researchers explore how these patterns can be delimited into meaningful categories, such as the creation of target audiences based on number of platforms a user visits, the ways the user engages with different platforms, and the number of connections a user maintains (Rozen et al., 2012). This study uses Brandtzaeg's (2010) unified media-user typology (MUT) to typify a collection of amateurs as social media users based upon how they understand the domain of interest, social palaeontology.

Analysing large samples of data, Brandtzaeg (2010) synthesized social media user typologies in which media use act as a proxy for expertise. Such typologies were termed social media personas and were described developmentally in the form of a pyramid, with Non-Users (those who do not use social media) serving as the base. As a user's expertise increases (based in large part on their frequency of social media use) they transition through the pyramid into different personas. The personas are typified by a set of generalizable characteristics. Sporadics represent users who either employ social media irregularly or are novices in their use whereas Lurkers are those who might use social media frequently, but do so in a passive manner. The two categories of Sporadic and Lurker can be collectively grouped as Onlookers, as both passive and irregular use is less sophisticated ( $\mathrm{Li}$ et al., 2007). Those who fit the persona of Entertainment users/Socializers often use social media to play games and to keep in touch with friends and family. Debaters/Instrumental users focus on acquisition of information, viewing social media as a utilitarian tool. Sparks/Advanced users, the persona delimited as having the most expertise, use social media for all forms that other personas utilize. Therefore, it is postulated that if people use their MUT-defined personas to learn palaeontology via social media then their mental models of the domain should contain attributes that are unique to and representative of these personas. Demonstrating this relationship could shed light upon the validity of MUTdefined personas and facilitate incorporation of social media into informal science learning.

\subsection{Mental Models}

The ways in which people understand and create meaning from interacting with the world can be elucidated through the expression of their mental models (Jih and Reeves, 1992; Johnson-Laird, 2013). Mental models are personal, abstract, internal neurological entities that humans actively build through cognition based upon their experiences in the world (Jonassen and Cho, 2008; Rapp, 2005). While mental models cannot be measured through direct means, they can be inferred and interpreted through their articulation as an expressed mental model.

Historically, five primary methods have been used to assess mental models: problem solving, verbal report, drawing, categorization, and conceptual pattern representation (Jonassen and Cho, 2008). Expressing a mental model allows an individual to describe their perceptions of a conceptual topic based upon their previous experiences (Ifenthaler, 2010). Furthermore, extensive research has scrutinized concept maps finding such structures to provide insight into the ways in which people perceive connections among topics and ideas (Kern and Crippen, 2008). Such structures are referred to as mental model structures, which can be broken into sequential, hierarchical, spidergrams ('hubs'), or other less frequently observed structures (Hanewald and Ifenthaler, 2014). For educational 
researchers, learning scientists, and user experience designers, expressed mental models (henceforth mental models) represent a critical artefact for inferring the impact of experiences and making judgements about learning.

Using mental model theory, this study began with the conjecture that based upon prior knowledge and experience, amateurs would have distinct mental models of social palaeontology (Chi et al., 1981; Schnotz and Kürschner, 2008) and that personal use of social media would have had an influence on these models (Bandura, 2001; Haythornthwaite, 2005).

\subsection{Social Media Personas}

Context-specific patterns of social media platform use have led to incongruous descriptions of social media users (Brandtzaeg, 2010). While it stands to reason that members of a community have similar perceptions, the platform for their interactions offer such members the capacity to interact in a multitude of ways (Gibson, 1986; Lovari and Parisi, 2014). User typologies (i.e. personas) are overarching explanations established by collating large swathes of individual user data related to patterns of exploration and social media preferences (Brandtzaeg, 2012). User typologies can correlate to personality traits such as extraversion and narcissism and have been identified by market researchers who tailor their content to reach the widest markets through targeted campaigns (Amichai-Hamburger and Vinitzky, 2010; Rozen et al., 2012; Vaynerchuk, 2013). The variable nature of interaction is marked by high, medium, low, and no interaction (Grabowicz et al., 2012). While nonusers do not participate in social media, extensive research has been completed on the phenomenon of 'lurking' or 'lurkers' in which social media users appear on a social media site yet do not engage with the content in a measurable way, unless they perceive a benefit to themselves (e.g., commenting) (Nonnecke et al., 2006; Nonnecke and Preece, 2000; Wasko and Faraj, 2005; Yeow et al., 2006).

\section{Methodology}

This study's methodology took the form of a qualitative multiple case study (Merriam, 2009) with MUT-defined social media personas serving as the individual case criteria. The study was completed as the initial component to usability testing of the beta version of myFOSSIL, an online community site for social palaeontology (www.myfossil.org). The outcome of this work intended to serve two purposes: (a) to assess the MUT's capacity for differentiating community participants and (b) to further contemporary understanding of the needs, values, interests, and perceptions of amateurs in relation to the goal of designing an online space to support science learning.

The convenience sample of participants was recruited via email using snowball sampling (Goodman, 1961) through the presidents of five fossil clubs/societies in a southeastern state in the United States. After each president sent an encouraging email to their membership, the research team received contact information for potential participants. These individuals subsequently consented to participate in the study and became the participants (N=9) (Table 1). Gender-neutral pseudonyms and pronouns (e.g. 'they' and 'their') are used purposefully to describe participants so as to protect their identities within the amateur palaeontological community. Following consenting to participate, the participants completed an intake survey which was used to further verify their amateur 
status and to assign them to a category of social media persona. Thus, the cases were bounded by the intent to understand the thinking of a collection of amateur palaeontologists, who, through their positive response to recruitment and willingness to participate, had an interest in supporting the successful design of an online community dedicated to social palaeontology.

Social media personas were assigned based upon each participant's response to a set of five multiple choice questions that were created to fit the social media typologies described by Brandtzaeg (2010) and Rozen et al. (2012) (Appendix A). The primary question used in assigning personas required participants to choose a quote that they felt best represented their use of social media. For example, in the case of the No Show/Non-users, participants chose the quote, 'I don't use social media' indicating fully that they did not utilize social media in any capacity, whereas for Onlookers/Lurkers, participants chose either 'I don't check social media because I don't find it worthwhile' or 'I check social media, but I don't post a lot of things.' Participants who chose the quotes associated with Onlookers/Lurkers were therefore indicating they used social media, but were troubled by some aspect of it (e.g. the 'worth' of it) or made some effort to browse and consume only. Additional questions concerning frequency and type of use (including use of Facebook and Twitter) and the number of connections participants had on social media were used as corroborating evidence.

Some personas from Rozen et al. (2012) and the MUT described by Brandtzaeg (2010), overlapped, therefore, these personas were combined, such was the case for Onlookers/Lurkers. Ideally, the study had the potential for five cases, one for each of the personas. However, two of the potential cases, Sparks \& Advanced users and

Debater/Instrumental users, represent less than 15 percent of the population (Brandtzaeg, 2012) were not found to be present in the sample and thus were not included in the analysis. Therefore, the analysis was based upon three cases, each representing different social media personas with a varying number of participants in each case with slightly different demographics: Case One, the No Show/Non-users (i.e., Non-Users); Case Two, the Onlookers/Lurkers (i.e., Onlookers); and Case Three, the Entertainment users/Socializers (i.e., Socializers). All participants were age 35 or older and came from a variety of professions, including education, government, and for profit industries (Table 1). For a more complete description of amateur palaeontologists in the United States, see Crippen et al. (2016) and MacFadden et al. (2016).

[Table 1 about here]

\section{Data Sources and Analysis}

Data sources included the intake survey, a set of mental models in the form of an arrangement of cards with social media conventions and definitions, and transcripts of participants narrating their arrangements of cards (including their rationale for choices). The 20-item intake survey consisted of 12 multiple-choice questions and 8 open-ended questions. Multiple-choice questions addressed the participant's age, palaeontological experience, and social media experience. Open-ended questions queried participants about their ideas and preconceived notions related to social palaeontology. Participants completed a series of card sort think-aloud activities using a collection of twelve social media conventions (e.g., like, share, blog, hashtag) and their definitions (Lundgren and 
Crippen, 2015). Each task asked participants to use the conventions to express their mental models for using social media to accomplish each of the four activities of social palaeontology (Table 2), to think aloud while doing so, and to provide a verbal explanation of their creations. The card arrangements were photographed as a digital artifact and the think aloud was audio recorded and transcribed verbatim.

\section{[Table 2 about here]}

All data were collected on-location, where a member of the research team travelled as far as 225 miles in order to meet participants at a location near where they lived. Following completion of the intake survey, a researcher first asked the participant to envision a website of their own design that centred on the science of palaeontology. Then, sequentially for each of the four activities, participants were prompted to choose cards displaying social media conventions, arrange the cards meaningfully, and then assign definitions to the conventions. The prompt was, 'Using the cards, how would you accomplish the goal of (activity + description) on this website?' This resulted in four expressed models, with one transcript for each participant.

Data analysis involved constant comparison and triangulation of findings among the three sources (Saldaña, 2013). The survey data was analysed first in order to establish themes, which were then refined through analysis of the model structures and transcripts. The procedures recommended by Hanewald and Ifenthaler (2014) were used for determining the structure of models, whereas the content of the models was assessed using a form of visual content analysis (Rose, 2012). All coding was first done independently by two researchers, then discussed to consensus in a meeting of the research team (Saldaña, 2013). The entire five-member research team reviewed all coded passages together and collaboratively constructed operational definitions of themes and codes.

To address the initial research question, the results for all participants were first reviewed holistically, regardless of and blinded to social media persona, and wrote a summary. For the second research question, the results were separated into three cases based upon social media personas, reviewed them individually, and wrote independent case summaries. Finally, the results for all three cases were compared against each other in a cross-case analysis, which resulted in a final summary (Merriam, 2009). Each of the summaries is presented next as findings.

\section{Findings}

\subsection{Amateur Palaeontologists' Mental Modelling of Social Palaeontology}

Participants used different social media conventions for describing how they would accomplish the goals for each of the activities of social palaeontology (Figure 1). Participant accuracy in applying the correct definitions to these conventions was quite low at 54\%. Aside from providing additional evidence for these activities as separate and distinct, this level of analysis indicates the primary social media conventions that participants would expect to use for each activity. For example, for collaborating with others and sharing information (i.e., Converse), participants would primarily choose 'blog', 
'chat', and 'share'. For identifying something of interest to them (i.e., Consume) they would rely on 'bookmarking'. Though these patterns indicate preferences, with one exception (no use of 'like' for Observe), participants used all of the conventions for each activity.

[Figure 1 about here]

A structural analysis of the arrangement of conventions revealed that participants were most likely to create sequential models (Figure 2). These linear forms of representation are indicative of a relatively simple and straightforward understanding that is characterized by a beginning, a single unidirectional path linked as a chain, and an end (Figure 3). For example, study participant Reagan indicated that in order to manage groups of people and things (i.e., Connect),

'you'd have like a webinar where you came to find the information, you guys would chat and discuss, and then your comments about whatever it was you were trying to find you would leave and then hash tag it so other people could come and find it' (Reagan, transcript).

[Figure 2 about here]

The second-most identified structure was that of a hierarchical model, which had a single starting point and a general unidirectional path to an end, but included branches inbetween. The branches, which are unique to this structure, indicate levels of subordinate and superordinate relationships among concepts (Hanewald and Ifenthaler, 2014). This structure is more diffuse than that of a sequential structure and, if it results from prompting for an expansive explanation of a topic, is considered more advanced (Figure 3). The hierarchical structure was produced when participants were differentiating the use of distinct conventions in their models as an option under a single pathway. For example, consider study participant Taylor's description for how they would manage groups of people and things (i.e., Connect), which began with the convention of a forum and flowed from it,

'Ok, forum, and once you have forum - everyone's provided with a forum, right - so you go into a forum and you have different themes and each theme has subdivisions and each subdivision has the actual conversations' (Taylor, transcript).

[Figure 3 about here]

The content analysis of the models resulted in eleven themes. Through the recursive coding process, themes came to be associated and represented hierarchically based upon how the terms are distinguished ontologically by amateur palaeontologists (Figure 4).

[Figure 4 about here]

Following coding, themes were classified as either major or minor based upon the degree to which they were identified (Tables 3 and 4). When these themes are related to 
the activities of social palaeontology, a distinct pattern is apparent for each (Figure 5). For example, the themes of 'exchange' and 'documenting' are most strongly associated with the activity of Converse, while 'curation' and 'exchange' are most strongly associated with Consume. Though the model structures suggest a predominantly simplistic approach, these patterns offer a palaeontology-based explanation for the participants' intent in their use of different conventions for achieving the goals for these activities (Figure 1). Thus, if motivated to identify something at a social palaeontology website that interested them (i.e. Consume), these participants would be most likely to employ a simple, straightforward approach to organize this information (i.e., 'bookmarking) or to ask for more about it from others (i.e., exchange).

\section{[Table 3 and Table 4 about here]}

The minor coded themes appeared less often overall within the activities of social palaeontology, but can still clarify participant intent and reasoning or can illuminate troubles that participants had with the task(s). Specifically, the minor themes of 'tension', a disconnect in the person's views of the task and their persona or mental model, and 'interesting comment', remarks that did not fit with other codes but were unique enough in some capacity to bear marking, are intriguing. Both of these themes are consistent with prior research suggesting that when constructing mental models, participants may struggle to communicate their internal representations (Ifenthaler, 2010). Within the current study, these struggles were classified as the minor themes of 'tension.' An example of this is participant Parker saying, 'I was looking for something else and I can't find it exactly...' (Parker, transcript). In addition to their tensions, participants sometimes remarked on the mental models themselves, such as when Reagan described different ways people could construct models, saying,

'It's funny how different our brains track. [Laughter] It really is; the way you go about things and the way I go about things. Are you paying attention to any of this? You could learn a lot. I'm just saying it's just totally different; the words we choose, the steps we do is totally different. There's a couple similarities but it's... There's no right or wrong thing; it's just an observation. It's just different' (Reagan, transcript).

Such remarks, which were few, are unique in that they do not necessarily relate to participant outlooks on palaeontology, but they can provide insight into participant metacognition.

\section{[Figure 5 about here]}

In summary, the mental models of social palaeontology for the entire group of participants were most likely sequential and straightforward, involving a unique use of conventions for each activity. Combining this with the themes of the content analysis, a palaeontology-based explanation for their models can be inferred, especially as participant tensions were rarely coded. 


\subsection{The relationship between mental models and individual personas}

With the subsequent sections, participant mental models are related to each social media persona as individual cases, then with the final section, a cross-case analysis is used to compare the personas against each other.

\subsubsection{Case One: Non-Users}

As elucidated by the MUT, Non-Users are those who do not use social media, are unskilled in such, or unwilling to participate in it. In line with the MUT, participant Riley, the NonUser identified in this study, often relied on their understanding of collaboration in the real world to inform their view of social palaeontology. Indeed, Riley viewed the social palaeontological activities as a chance to glean information to share in-person, saying ' $I$ would like to have the ability to take [information] from the system so I can share that with anybody I would be working with' (Riley, transcript). In lieu of utilizing the social media conventions that were provided for the modelling task, Riley chose to create new ones, including 'website/membership' and 'photo references' to describe activities. When Riley did use the provided social media conventions, they averaged almost ten conventions per activity $(n=9.5)$, but, as Table 5 shows, Riley was very inaccurate in matching conventions with definitions, averaging two percent accuracy rate. Such low accuracy coupled with the need to create personal, non-standard conventions is indicative of a poor understanding of social media. Furthermore, Riley did not acknowledge any benefits for collaboratively building knowledge in an online environment, seemingly desiring an online resource repository, saying, 'I would like to be able to [input] let's say for example wooly mammoth. I'd like to be able to put that header in and see what current research is currently available' (Riley, transcript). This quote indicates a narrow view of social palaeontology, one in which the online environment is used so that individuals can remove information from the system in order to build their own knowledge, as opposed to collaboratively building knowledge with others. In total, Riley's modelling of social palaeontology with poor accuracy of social media conventions, proclivity towards individualized usage, and penchant for non-digital practise aligns with the MUT in regards to Non-Users.

\subsubsection{Case Two: Onlookers}

Onlookers are those who have used social media but might be new to it or had used social media in less traceable manners (i.e., lurking). In social media environments, the MUT postulates that these users would consume media and browse content instead of contributing content themselves. This case of participants described social palaeontology predominantly as a way to gain information about the science of palaeontology through reading news stories. For example, participant Jean described their interest as 'reading other people's experiences' about palaeontology (Jean, Survey Q25). For the model construction tasks, this group averaged just over eight conventions per activity, and as Table 5 shows, they accurately matched conventions to definitions 55 percent of the time. Such accuracy indicates an emerging understanding of common social media conventions. Furthermore, this group of Onlookers expressed interest in curating social palaeontological content, most often for themselves. Kerry viewed bookmarks as a way to curate content, but felt uncomfortable sharing their interest with others, declaring: 'As soon as I found what I wanted...I would bookmark it immediately. I don't really add likes or share with a 
friend' (Kerry, transcript). Kerry's hesitancy to share in a public manner is rooted in the Onlooker persona: being able to utilize the Internet in less traceable ways affords security (perceived or real). In summary, Onlookers' modelling of social palaeontology with their consumption of stories, their inclination toward lurking, and their midrange levels of accuracy align with MUT-specified descriptions.

\subsubsection{Case Three: Socializers}

As predicted by the MUT, Socializers would use social media to keep in touch with friends and family and/or play games. In this study, Socializers focused on conceptualizing social palaeontology as a means to communicate with others who shared their interests and as a way to further their knowledge. Indeed, social curation of content drove the majority of their depictions of social palaeontology, as seen in their use of the term hashtag. Participant Parker regarded hashtagging as a means for identification of fossils, saying is really important in my opinion because like...I don't have an idea what [something] is, so when I open the website, I [follow a hashtag, saying] "oh, that is shark teeth or that is horse teeth" (Parker, transcript). Participant Pat referenced building content knowledge via communicating with others, indicating that status updates allowed people to 'access their comments to one another' and to facilitate online meetings with people of similar interests (Pat, transcript). Socializers averaged only 5.5 conventions per activity for the model construction tasks. However, a convention was always paired with definitions, but only accurate 59 percent of the time (Table 5). Utilizing less social media conventions on average than the other cases might indicate that this group has specific and pre-defined ways of using social media due to their familiarity with the environment. Furthermore, Socializers, such as Taylor, viewed social palaeontology as having multiple avenues for participation and contribution where 'everyone could offer their ideas, and could potentially learn or be a teacher to other members' (Taylor, Survey Q25) A fully participatory and contributory environment reflects the Socializer persona: wanting to communicate with others through a social media platform. With their preference for communicating with others, Socializers appear to align directly with conventions stipulated by the MUT. The MUT also indicates that Socializers should have higher levels of expertise; however, the lack of accurate conventions for these Socializers do not relay this.

\subsection{A Cross-Case Analysis of Mental Models among Social Media Personas}

The structures of case participants' mental models were minimally related to their social media personas (Figure 6). Sequential models were the most common structure found, with higher proportions for Onlookers $(75 \%)$ and Socializers $(67 \%)$. In addition, Socializers constructed the most diverse variety of models, yet Onlookers also created hierarchical models and a few spidergrams. Riley, the Non-User, created an equal mixture of sequential $(50 \%)$ and hierarchical mental models $(50 \%)$ for the different activities.

[Figure 6 about here]

For three of the four activities, the composition of the models was found to be related to the social media persona of the case participants. When the model structures were sequential, there was an inverse relationship between the number of conventions used and the level of social media persona; the sequential models from the Socializers used fewer 
conventions than those from the Onlookers, who used fewer than the Non-User. For example, for the activity of Connect, the Non-User utilized 12.0 conventions, Onlookers averaged 8.0 conventions, and the Socializers averaged 3.5 conventions. This pattern was observed within the activities of Connect, Converse, and Observe. For Consume, the average number of conventions used by Onlookers and Socializers for sequential models was the same, but significantly less than that of the Non-User. If the model structures were something other than sequential, there was no discernable relationship.

For the majority of the data, sparse support was found for a relationship between social media persona and the way participants described their understanding of social palaeontology. However, differences among the cases were identified for the themes of 'exchange' and the minor themes of 'membership,' 'curation,' and 'news.'

Exchange - the act of interacting with others - was intimately tied to the ways in which participants viewed membership in online social environments. Although membership was coded as a minor theme, it was almost always identified in conjunction with the major theme of exchange. For example, Riley, the Non-User, described the ways in which people could interact as interest matching, so that social spaces could be used by 'people who have similar interests,' (i.e. integrating the themes of exchange and membership) (Riley, transcript). Joining would involve declaring your interests so that exchange would entail interest-based, one-to-one chats. Riley wanted to 'be able to see and contact current researchers who may be able to answer or help refine my research idea' (Riley, transcript). This Non-User perspective contrasted strongly with that of the three Socializers, Taylor, Pat, and Reagan, who viewed membership as a means of security, for protecting the exchange of information, and for conversation among multiple people. Taylor alluded to security when discussing membership by saying they would feel better if, 'I came upon this website and I joined it and it was free and they ask you for a valid email' (Taylor, transcript). Pat echoed this sentiment, writing: 'I would be like to be able to be certain that my information would be secure so I might want to do so under a security name or code' (Pat, Survey Q22). Reagan also wanted a layer of security, writing that they wanted some information on the website to be 'off limits to a passerby' (Reagan, Survey Q24). According to characteristics affiliated with the Socializer persona, socializers enjoy connecting with new people and with those who have similar interests (Brandtzaeg, 2010). Socializers' descriptions of security and controlling access to information might highlight their previous experiences with social media, in that the communication space has to be safe and interest-specific before they create connections.

Within the theme of 'exchange,' Socializers strongly emphasized interactions with others, especially those interactions that encouraged multiple participants. Communicating with multiple people can be daunting to some, which relates to the Socializers' anxiety about security. Pat indicated: 'I don't tend to blog people I don't know' (Pat, transcript). However, when Socializers reached a comfort level, they expected to find a secure site with information exchange through participation and contribution of all members. Taylor succinctly portrays this process saying, 'everyone could offer their ideas and could potentially learn or be a teacher to other members' (Taylor, transcript). Alex uses the metaphor of a meeting to describe their experience with exchanging information, telling the researcher,

'I start a meeting with asking for comments; I take those and I share with that group the experience or expertise I have in that area and then we'll discuss it and that's when you start listening; listening is very important. First you listen to their comments, you share your knowledge, then let the discussion begin because by 
sharing your knowledge they're going to come up with...other ways of doing something so then we can discuss and go back and forth about it' (Alex, transcript).

Socializers delimit the theme of 'exchange' by emphasizing multiple participants communicating about topics, whereas the Non-User restricts 'exchange' to individualistic communications; yet, both constrain these concepts with membership parameters. These views of exchange are interpreted as reflections of the social media personas.

The themes of 'curation' and 'documenting' were also found to be related to social media personas. 'Curation' and its sub-theme of 'documenting' are an amalgamation of digital practice (i.e., digitization of fossils and associated fossil locality data) as well as real-world forms by which fossilized specimens are organized into a collection. For the Non-User, curation and documenting were structured processes in which the site and its contents were static resources for comparison. To curate, Riley described searching the site for information, indicating, 'I'd like to be able to put [wooly mammoth] in and see what research is currently available...then I would like to have the ability to take that from the system' (Riley, transcript). This personal process of inputting queries to then extract information from the system is akin to information processing and lacks a social dimension. Furthermore, when describing the process of documenting, which was defined as adding data to contributions to make them more meaningful, Riley indicated, 'I would want the ability to bookmark and know that I can get back to it' (Riley, transcript). Such self-focused behaviors are indications that for a Non-User, curation and documenting are strictly individualistic practices by which a single user maintains and organizes their own information, which is not considered nor intended to have value for others. These individualistic practices align with the MUT, which suggests that Non-Users have no interest in social media.

In contrast to Non-Users, the Onlookers have medium skill levels and use social media with an emerging sense for using a space with others in mind. Participants Kerry and Jean identified the convention of bookmarking as a key component of curation. Kerry described the curatorial process by using the social media convention 'bookmarking' and hesitantly described it as a form of sharing, telling the researcher, 'I might share once I'm convinced that it's an appropriate set of information. Yeah, I might email it to someone' (Kerry, transcript). Kerry's description of using a site to organize and maintain information is similar to that of Riley, the Non-User, in that Kerry focused on saving information for individualized use, yet Kerry emphasized a step in the process that Riley did not: curating with the intent to share with others. Jean also demarcates the Onlookers from other personas when describing the social media convention of 'hashtag.' Jean provided a succinct and correct definition for hashtag but did not place this definition in the mental model, and, immediately after describing the convention correctly, told the researcher, 'I have no idea what hashtags are' (Jean, transcript). While Jean understood that a hashtag could be used by oneself and by others to curate information, Jean indicates that this form of curation is not necessarily within their purview for organizing and maintaining information on the site. Both Kerry and Jean's responses concerning curation embody the Onlooker persona: some expertise with social media, consumption of information, and hesitancy in sharing with others (Brandtzaeg, 2010).

In contrast to the Non-User and the Onlooker personas by demonstrating a more developed expertise, the Socializers depicted curation and documenting in ways that equally valued making information useful to both themselves and to others. For instance, when describing the process of curation, Reagan indicated, 'I would probably write a 
blog... about the information I would want to remember ....anybody can gain access to it' (Reagan, transcript). For Socializers, curation was making content equally useful for themselves as well as for others. Pat indicated that people could contribute 'from their own research, collect and study with creating and investigating a possible hypothesis about a topic' (Pat, transcript). Other Socializers, like Sidney, described using a Wiki: 'that way, it's an opportunity for everybody to kind of find a central location for the topic then search' (Sidney, transcript).

Differences in the descriptions of curation indicate that social media personas effect the ways in which amateur palaeontologists consider social palaeontology. Amateurs with more socially-based personas (e.g., Socializers) tended to view curation as a social process whereas those without a social basis (e.g., Onlookers) tended to think of curation as a way to compare resources.

'News,' a theme which was bounded by the concept of information dissemination, featured tiers of descriptions based on social media personas. Socializers, those users that sought to exchange information with one another, displayed the most interactive form of the theme of 'news.' Although dissemination was key to news, Socializers still required communicative elements. Pat embodies this concept when describing updates, telling the researcher that users 'would know that they could meet up at that particular time online and they could...access their comments to one another' (Pat, transcript). Parker also indicates that within news, discussion is necessary as it helps 'spread the news and definitely helps the website-that's my opinion' (Parker, transcript). These responses differ from those of the Onlookers and the Non-User, who viewed news as a more passive activity.

Onlookers described news as a straightforward process. Jean was especially clear, indicating that 'reading other people's experiences (Jean, Survey Q25)' could give users information about fossils and social palaeontology. Kerry described the process as spreading 'the word of an event or worthwhile trip (Kerry, Survey Q18)' demonstrating some similarities to the Socializers. However, Kerry's description did not explicitly include people within this description, instead focusing exclusively on the website, as though only the website itself could encourage information dissemination.

In some respects, Riley, the Non-User, indicated similar uses as the Onlookers. Riley related news directly to finding information about in-person events. This informationfinding was not interactive, as emphasized by their phrases, 'the ability to download information,' and wanting information about an 'upcoming conference related to your area of expertise' (Riley, transcript). Furthermore, Riley wanted news as information dissemination that did not have to be interacted with, claiming a blog 'by the researchers...just to be able to post and provide information would be very interesting' (Riley, transcript). In this quote about news, Riley embodied the Non-User social media persona: having little to no interest in interacting with others in a social, online environment.

\section{Discussion}

\subsection{Discussion of case and cross-case analysis of mental model structures}

Case participants demonstrated their personas in subtle ways through their mental models. For the Non-User, their lack of experience with social media and its consequences 
were quite apparent. Their mental models were more diffuse, inaccurate, and based around contrived ideas. Online spaces were viewed as resources for information, such as news or reference material to be used elsewhere; their role was that of consumer. Membership in such a site was important, but akin to interest matching in order to serve their personal benefit. No value was attributed to the potential for social interactions. Non-Users of social media are becoming less common in the developed world (Perrin, 2015), yet they still comprise a substantial part of the population. Thus, the mental models of such participants are of interest as they can inform researchers' and developers' conceptualizations surrounding appropriate content development.

Onlookers, those with some social media experience but in more casual ways, indicated a clear emphasis on vicarious learning, but also offered a unique perspective on the role of social interaction for increasing the value of information for others. For these participants, lurking - participating without contributing - was a clear strategy and took the form of reading news as well as the experiences of others. Lurking is a well-studied phenomenon (Nonnecke et al., 2006; Nonnecke and Preece, 2000): the MUT builds upon previous research by analyzing these users further and depicting the value of social learning as understanding experiences vicariously versus through direct social interaction. Adding new or qualifying information to existing information in order to increase its value (i.e. curation) was viewed as an acceptable and preferred social contribution. Membership offered a desired sense of security that promoted the intent to contribute socially. Social exchange was acceptable, but only after a necessary level of comfort was achieved. Bookmarking was perceived as a strategy for marking something so that might be shared later, once the value of the information had been established. Discussion was possible, but only in more secure private spaces.

Socializers demonstrated a clear value and need for making a personal contribution, intended for multiple other participants, as well as an expectation for the social contribution of others. As stipulated by the MUT, interaction with similarly-minded users was a key focus. As such, hashtagging was identified as an important strategy for making information more socially available. For Socializers, curation involved providing a much more substantial and robust contribution than simply tagging or commenting. Like Onlookers, the security from membership was also important for supporting social interactions. The Socializer perspective clearly valued social commentary and was based upon an expectation for finding the results of social engagement as well as for providing their own contribution. Social commentary can be indicative of community building, and as such, users with features embodied by Socializers are identified as keystones in the development of online communities (Kraut et al., 2012).

The results also offer some limited evidence for a relationship between amateur palaeontologists' social media personas and the structure and composition of their mental models. Regardless of persona, case participants were most likely to describe social palaeontology using a sequential model, but more advanced personas did so more often. Thus, the sequential model structure serves as an expression of expertise development that varies based upon media use (Ettenson et al., 1987). Case participants who report greater use of social media, and thus a more advanced persona, understand social palaeontology more holistically, which results in a more refined and straightforward approach (Bradley et al., 2006; Stains and Talanquer, 2008; Williams and Noyes, 2007). Considering the goals for the activities that were used to prompt participants, a sequential structure exemplifies a straightforward and efficient way to achieve the desired outcomes. 
Expertise development is also demonstrated by the number of conventions that were used in creating sequential models. As a person develops an understanding for a domain, they become better able to discern important elements and less likely to be distracted by trivial or unimportant features (Chi et al., 1981). The pattern of more advanced personas using fewer conventions for expressing their sequential mental models is indicative of producing knowledge through media use, the primary assumption supporting the MUT.

However, the high level of inaccuracy across cases when defining the conventions that were used in the models suggests that participants lacked a general understanding for their own thinking. Basically, participants could explain how they would accomplish a task, but were not able to accurately name and define the steps that they used in the process. This construct is recognized as knowledge of cognition - 'what individuals know about their own cognition or about cognition in general' (Schraw and Moshman, 1995, p. 354) and is one of two components defined as metacognition (generally, thinking about one's thinking). High levels of metacognition are a hallmark of successful and advanced learners, improving their ability to transfer knowledge across contexts (Pintrich, 2002). Low levels of metacognition are associated with learning environments that fail to make tacit knowledge explicit (Schraw et al., 2006). For these participants, the low level of metacognitive awareness while completing socially-based online activities associated with palaeontology is likely due to their lack of formal training in palaeontology.

\subsection{Limitations of the study}

We recognize that this study is not without its limitations. As a qualitative case study, the responses of the participants in this study are limited to their own experiences. Furthermore, the restricted participant pool can be seen as less generalizable than larger, quantitative studies. This exploratory, qualitative multiple case study includes a sample of amateur palaeontologists whose ages are 35 and older. Considering what is already known about amateur palaeontologists who participate in fossil groups, this study's group of participants is more age-diverse than those represented in fossils groups, whose average member age is 50 years of age or older (Crippen et al., 2016). The choice to exclude participant gender from the data analysis in order to protect participant identities limits the ability to make inferences based on gender. However, providing rich and thick descriptions of participant experiences, triangulating data, and examining data with a research group were employed in an effort to alleviate limitations (Merriam, 2009).

The use of a non-random sample of amateur palaeontologists, is merely one method that helps to create exploratory pathways for further research into the study of science learning in informal spaces. Sampling, which was severely limited by access to participants and potentially by the overall demographics of avocational palaeontologists, could be viewed as restricting case selection and skewing the sample based upon age. Participant age could have unexplored explanatory power. For example, for an older demographic, involvement in fossil groups (e.g., clubs or societies) could plausibly be an alternative to social media engagement and thus could account for some of the findings. Inclusion of younger participants could have helped explain the results.

This study advances the theory of media use as it relates to science for the purpose of learning in informal spaces as well as for paleontology social studies, an area that continues to develop. It does this by contextualizing the MUT, probing at the pieces that comprise each persona. While this study investigated the ways the MUT applied to participants in one context, it needs further contextualization in additional learning spaces, such as informal learning spaces including science museums or within other hobbyist groups such 
as birdwatchers. Contextualization of the MUT can also be advanced through explorations of its use in formal learning environments. Other research has shown that student learning improves when teachers design and customize web-based curriculum based on their students' work (Matuk et al., 2015). With the MUT in mind, these customizations of curriculum could encompass student learning and teacher development in the age of social media.

\subsection{Implications for website design}

This study, involving participants whose social media personas indicate limited experience and understanding of social media conventions, has implications for the overarching effort to design a digital habitat for social palaeontology, as well as for others with similar goals. Designing a website with these users in mind would include supports for them, such as providing the bookmarking convention for those users whose intentions are not inherently social. Further, supporting the practice of hashtagging and providing comment boxes will allow more social users (i.e. Socializers) to mark the content they find useful and use it for conversations with others. In sum, this means designing a site that allows Non-Users (or those unfamiliar with social media) to glean information from the system for the purpose of discussion outside of the online social system, gives Onlookers structure and support, and encourages Socializers to discuss content as well as place emphasis on the value of tagging. While this study is limited in that it did not include some of Brandtzaeg's (2010) originally-identified user typologies, it can be extrapolated that a successful social palaeontology site must be designed with these users' interests in mind as well. To assess this idea more fully, another study using a representative sample of users from across all the social media personas is recommended.

\section{Conclusion}

The purpose of this study was to explore the relationship between amateur palaeontologists' mental models of social palaeontology and their social media personas. Consistent with their level of expertise, the model structures were not overly complex, primarily defining social palaeontology as a sequential pattern of events. It was also determined that within these mostly sequential models, the conventions of social media were often inaccurately defined, even for those that were classified as having more advanced social media personas. This suggests that even as amateurs' social media personas increase in expertise, their actual descriptions of social media conventions do not convey such expertise. Lastly, it was determined that social media personas delimited amateur palaeontologists' descriptions of particular aspects of social palaeontology, namely 'curation,' 'exchange,' and 'news.' Amateur palaeontologists represent a seldom studied yet vital component to understanding interest-based informal science learning. This study serves as an example for social media and educational researchers who seek to provide more contextual evidence for the proposed universally-applicable MUT. In contextualizing the MUT, this study determined that the MUT accounted for little when exploring media users' capacity for science learning in informal spaces. 
Amichai-Hamburger, Y. and Vinitzky, G. (2010) 'Social network use and personality', Computers In Human Behavior, Vol. 26 No. 6, pp.1289 - 1295

Azevedo, F. S. (2013) 'The tailored practice of hobbiers and its implication for the design of interestdriven learning environments', Journal of the Learning Sciences, Vol. 22 No. 3, pp.462 - 510

Bandura, A. (2001) 'Social cognitive theory of mass communication', Media Psychology, Vol. 3 No.3, pp.265 - 299

Bell, P. et al. (2009) Learning Science in Informal Environments, National Academies Press, Washington, D.C.

Bismack, A. S., Arias, A. M., Davis, E. A. and Palincsar A. S. (2015) 'Examining student work for evidence of teacher uptake of educative curriculum materials', Journal of Research in Science Teaching, Vol. 52 No.6, pp.816 - 846

Bokor, J. R., Broo J. and Mahoney, J. (2016) 'Using fossil teeth to study the evolution of horses in response to a changing climate', The American Biology Teacher, Vol. 78 No.2, pp.166 - 169

Bonney, R., Phillips, T. B., Ballard, H. L. and Enck, J. W. (2015) 'Can citizen science enhance public understanding of science?', Public Understanding of Science, Vol. 25 No.1, pp.2 - 16

Bradley, J. H., Paul, R., and Seeman, E. (2006) 'Analyzing the structure of expert knowledge', Information \& Management, Vol. 43 No.1, pp.77 - 91

Brandtzaeg, P.B. (2012) 'Social networking sites: Their users and social implications - A longitudinal study', Journal of Computer-Mediated Communication, Vol. 17 No.4, pp.467 - 488

Brandtzæg, P.B. (2010) 'Towards a unified Media-user typology (MUT): A meta-analysis and review of the research literature on media-user typologies', Computers in Human Behavior, Vol. 26 No.5, pp.940 - 956

Chi, M. T. H., Feltovich, P. J. and Glaser, R. (1981) 'Categorization and representation of physics problems by experts and novices', Cognitive Science, Vol. 5 No.2, pp.121 - 152

Chiou, G-L. and Anderson O. R. (2010) 'A study of undergraduate physics students' understanding of heat conduction based on mental model theory and an ontology-process analysis', Science Education, Vol. 94 No.5, pp.825 - 854

Crippen, K. J., Ellis, S., Dunckel, B. A., Hendy, A. J. W., and MacFadden, B. J. (2016) 'Seeking shared practice: A juxtaposition of the attributes and activities of organized fossil groups with those of professional paleontology', Journal of Science Education and Technology, Vol. 25 No.5, pp.731 - 746

Crippen, K. J., Dunckel, B. A., MacFadden, B. J., Ellis, S., and Lundgren, L. (2015) 'A framework for social paleontology via online community space', in Proceedings of E-Learn: World Conference on E-Learning in Corporate, Government, Healthcare, and Higher Education 2015, Association for the Advancement of Computing in Education, Chesapeake, VA, pp.305-311

Ettenson, R., Shanteau, J. and Krogstad, J. (1987) 'Expert judgment: Is more information better?', Psychological Reports, Vol. 60 No.1, pp.227 - 238

Falk, J.H. and Dierking, L. D. (2013) The Museum Experience Revisited, $2^{\text {nd }}$ ed., Left Coast Press, Inc., Walnut Creek, CA.

Falk, J.H. and Storksdieck, M. (2010) 'Science learning in a leisure setting', Journal of Research in Science Teaching, Vol. 41 No.2, pp.194 - 212

Grabowicz, P. A., Ramasco, J. J., Moro, E. et al. (2012) 'Social features of online networks: the strength of intermediary ties in online social media.' PLoS One, 7(1) [online] e29358 (Accessed 31 January 2015).

Gibson, J. J. (1986) The Ecological Approach to Visual Perception, Lawrence Erlbaum Associates, Hillsdale, NJ.

Goodman, L.A., (1961) 'Snowball sampling', The Annals of Mathematical Statistics, Vol. 32 No.1, pp. $148-170$ 
Hanewald, R. and Ifenthaler, D. (2014) Digital knowledge mapping in educational contexts', in Ifenthaler, D. and Hanewald, R. (Eds.), Digital Knowledge Maps in Education, Springer New York, New York, pp.3-15.

Haythornthwaite, C. (2005) 'Social networks and Internet connectivity effects', Information, Communication \& Society, Vol. 8 No.2, pp.125 - 147

Ifenthaler, D. (2010) 'Relational, structural, and semantic analysis of graphical representations and concept maps', Educational Technology Research and Development, Vol. 58 No.1, pp.81 - 97

Jih, H. J. and Reeves, T. C.. (1992) 'Mental models: A research focus for interactive learning systems', Educational Technology Research and Development, Vol. 40 No.3, pp.39 - 53

Johnson-Laird, P. N. (2013) 'Mental models and cognitive change', Journal of Cognitive Psychology, Vol. 25 No.2, pp.131 - 138

Jonassen, D and Cho, Y. (2008) 'Externalizing mental models with mindtools', in Ifenthaler, D. et al (Eds.), Understanding Models for Learning and Instruction, Springer, New York, pp.145-159.

Jones, M. G., Corin, E. N., Andre, T., Childers, G.M., and Stevens, V. (2016) 'Factors contributing to lifelong science learning: Amateur astronomers and birders', Journal of Research in Science Teaching, Vol. 54 No.3, pp.412 - 433

Kern, C and Crippen, K. J. (2008) 'Mapping for conceptual change', The Science Teacher, Vol. 75 September, pp. 32 - 38

Kraut, R. E., Resnick, P. and Kiesler, S. (2012). Building Successful Online Communities, MIT Press, Cambridge, MA.

Li, C. et al., (2007) Social technographics ${ }^{\circledR}$ mapping participation in activities forms the foundation of a social strategy. [online] Report E-RES42057, Forrester, Cambridge, MA. https://www.forrester.com/report/Social+Technographics/-/E-RES42057 (Accessed 18 September 2017)

Lovari, A and Parisi, L. (2015) 'Listening to digital publics: Investigating citizens' voices and engagement within Italian municipalities' Facebook Pages', Public Relations Review, Vol. 41 No.2, pp.205 - 213

Lundgren, L and Crippen, K. J. (2015) 'Designing for social paleontology: An exploratory study of citizen mental models', in: The Proceedings of E-Learn: World Conference on E-Learning in Corporate, Government, Healthcare, and Higher Education 2015, Association for the Advancement of Computing in Education (AACE), Chesapeake, VA, pp.849-858

MacFadden, B. J., Lundgren, L., Crippen, K. J., Dunckel, B. A. and Ellis, S. (2016) 'Amateur paleontological societies and fossil clubs, interactions with professional paleontologists, and the rise of $21^{\text {st }}$ century social paleontology in the United States', Palaeontologica Electronica, Vol. 19 No.2, $1 \mathrm{E}$

Matuk, C.F., Linn, M.C. and Eylon, B. (2015) 'Technology to support teachers using evidence from student work to customize technology-enhanced inquiry units', Instructional Science, Vol. 43 No.2, pp.229 - 257.

Merriam, S. B. (1991) Case Study Research in Education: A Qualitative Approach. Jossey-Bass Inc., San Francisco.

Miller-Rushing, A., Primack, R., and Bonney, R. (2012) 'The history of public participation in ecological research', Frontiers in Ecology and the Environment, Vol. 10 No.6, pp.285 - 290

Moran, S., C. McLaughlin, MacFadden, B. J., Jacobbe, E., and Poole, M. (2015) 'Third-grade students examine ancient organisms in modern times', Science and Children, Vol. 53 No.4, pp. $62-67$

Nonnecke, B and Preece, J. (2000) 'Lurker demographics: Counting the silent', in: Mynatt, E. et al (Eds.), Proceedings of the SIGCHI Conference on Human Factors in Computing Systems, ACM, New York, pp.73-80. 
Nonnecke, B., Andrews, D., and Preece, J. (2006) 'Non-public and public online community participation: Needs, attitudes and behavior', Electronic Commerce Research, Vol. 6 No.1, pp.7 $-20$

Perrin, A. (2015) Social media usage: 2005-2015, Pew Research Center.

Pintrich, P. R. (2002) 'The role of metacognitive knowledge in learning, teaching, and assessing', Theory into Practice, Vol. 41 No.4, pp.219 - 225

Racaniello, V. (2010) 'Social media and microbiology education', PLoS Pathogens, Vol. 6 No.10, e1001095

Rapp, D. N. (2005) 'Mental models: Theoretical issues for visualizations in science education', in Gilbert, J. K. (Ed.), Visualizations in Science Education, Springer, New York, pp.43-60.

Rose, G. (2012) Visual Methodologies: An Introduction to Researching With Visual Materials. Sage Publications Ltd, London.

Rozen, D., Askalani, M. and Senn T. (2012) Staring at the sun: Identifying, understanding and influencing social media users, Aimia.

Saldaña, J. (2013) The Coding Manual for Qualitative Researchers, $2^{\text {nd }}$ ed., SAGE ,Los Angeles.

Schnotz, W and C. Kürschner, C. (2008) 'External and internal representations in the acquisition and use of knowledge: visualization effects on mental model construction', Instructional Science, Vol. 36 No.3, pp.175 - 190

Schraw, G., Crippen, K. J., and Hartley, K. D. (2006) 'Promoting self-regulation in science education: Metacognition as part of a broader perspective on learning', Research in Science Education, Vol. 36 No.1-2, pp.111 - 139

Schraw, G and Moshman, D. (1995) 'Metacognitive theories', Educational Psychology Review, Vol. 7 No.4, pp.351 - 371

Stains, M and Talanquer, V. (2008) 'Classification of chemical reactions: Stages of expertise', Journal of Research in Science Teaching, Vol. 45 No.7, pp.771 - 793

Vaynerchuk, G. (2013) Jab, Jab, Jab, Right Hook, $2^{\text {nd }}$ ed., HarperBusiness, New York.

Wasko, M. M and Faraj, S. (2005) 'Why should I share: Examining social capital and knowledge contribution in electronic networks of practice', MIS quarterly, Vol. 29 No.1, pp.35 - 57

Wenger, E., White, N. and Smith, J.D. (2009) Digital Habitats: Stewarding Technology for Communities, CPsquare, Portland, OR.

Williams, D. J and Noyes, J.M. (2007) 'Effect of experience and mode of presentation on problem solving', Computers in Human Behavior, Vol. 23 No.1, pp.258 - 274

Yeow, A., Johnson, S. and Faraj, S. (2006), 'Lurking: Legitimate or illegimate peripheral participation?' in Twenty Seventh International Conference on Information System Proceedings, Curran Associates, Inc., Red Hook, NY, pp. 967-982.

Zhao, X., Lampe, C. and Ellison, N. B. (2016), 'The social media ecology: user perceptions, strategies and challenges' in Proceedings of the 2016 CHI Conference on Human Factors in Computing Systems - CHI '16. ACM Press, New York, pp. 89-100. 
Mental models and social media personas: A case of amateur palaeontologists

\section{Tables, Figure Captions, and Figures}

Table 1 Case definitions, including social media persona selection criteria, participant descriptions and demographic information.

\begin{tabular}{|c|c|c|}
\hline Case & $\begin{array}{l}\text { Descriptions based upon social media persona } \\
\text { (Brandtzaeg, 2012; Rozen et al., 2012) }\end{array}$ & $\begin{array}{l}\text { Participant Pseudo-names \& } \\
\text { demographics }\end{array}$ \\
\hline 1 & $\begin{array}{l}\text { No Show/Non-User } \\
\text { 'I don't use social media' }\end{array}$ & Riley, Education, 65+ \\
\hline 2 & $\begin{array}{l}\text { Newcomer / Sporadic / Onlooker/ Lurker } \\
\text { 'I don't check social media because I don't find it } \\
\text { worthwhile' 'I check social media, but I don't post a } \\
\text { lot of things' }\end{array}$ & $\begin{array}{l}\text { Jean, Government, 55-64 } \\
\text { Kerry, Photographer, 55-64 }\end{array}$ \\
\hline 3 & $\begin{array}{l}\text { Cliquer / Mix \& Mingler / Socializer } \\
\text { 'I use social media to exchange information and } \\
\text { check in with people' AND 'I use social media to } \\
\text { post about my day, I check in with others. I'm always } \\
\text { keeping up.' }\end{array}$ & $\begin{array}{l}\text { Alex, Retired, 65+ } \\
\text { Parker, Health care, 55-64 } \\
\text { Pat, Teacher, 55-64 } \\
\text { Reagan, For profit, 45-54 } \\
\text { Sidney, For profit, 45-54 } \\
\text { Taylor, For profit, 35-44 }\end{array}$ \\
\hline 4 & $\begin{array}{l}\text { Sparks / Advanced User } \\
\text { 'I don't want to miss anything, so I'm always } \\
\text { checking my social media' }\end{array}$ & None \\
\hline 5 & $\begin{array}{l}\text { Debater / Instrumental User } \\
\text { 'I use social media to read news and stories' }\end{array}$ & None \\
\hline
\end{tabular}

Table 2: Social palaeontology-based activities and their descriptions (Crippen et al., 2016).

\begin{tabular}{ll} 
Activity & Description \\
\hline Consume & Identifying something at the site that interests you \\
Connect & Managing groups of people and things \\
Observe & Recording and maintaining information about things from the real-world \\
Converse & Collaborating with others and sharing information \\
\hline
\end{tabular}


Table 3: Major coded themes across three types of collected data

\begin{tabular}{|c|c|c|c|}
\hline Theme & $\begin{array}{l}\text { Coded } \\
\text { Instances }\end{array}$ & $\begin{array}{l}\text { Operational } \\
\text { Definition }\end{array}$ & $\begin{array}{l}\text { Coded } \\
\text { Example }\end{array}$ \\
\hline Exchange & $100(21 \%)$ & $\begin{array}{l}\text { Interacting or } \\
\text { connecting with } \\
\text { others, group } \\
\text { learning, } \\
\text { feedback }\end{array}$ & $\begin{array}{l}\text { 'everyone could offer their ideas, and could } \\
\text { potentially learn or be a teacher to other } \\
\text { members.' (Taylor, K2U82, Survey q25) }\end{array}$ \\
\hline Curation & $100(21 \%)$ & $\begin{array}{l}\text { Utilizing the } \\
\text { platform to } \\
\text { organize and } \\
\text { maintain } \\
\text { information }\end{array}$ & $\begin{array}{l}\text { 'find resources and access them to actually } \\
\text { collect and prep my own found fossils.' } \\
\text { (Pat, BPUJC, Survey Q25) }\end{array}$ \\
\hline Documenting & $76(16 \%)$ & $\begin{array}{l}\text { Adding data, } \\
\text { including } \\
\text { pictures in a } \\
\text { meaningful way: } \\
\text { reacting to } \\
\text { contributions of } \\
\text { others }\end{array}$ & $\begin{array}{l}\text { 'Favorites is like you put all your favorites } \\
\text { so if somebody were looking and say this is } \\
\text { favorites so that means most of the things } \\
\text { that people will see so I put that in there.' } \\
\text { (Parker, CO2GG, Transcript) }\end{array}$ \\
\hline News & $72(15 \%)$ & $\begin{array}{l}\text { Reaching broad } \\
\text { audiences via } \\
\text { news and } \\
\text { information } \\
\text { dissemination } \\
\text { reading a blog }\end{array}$ & $\begin{array}{l}\text { 'The following has to be there; you're } \\
\text { going to need information so that people } \\
\text { can find out what's going on or what's } \\
\text { happened in the past and this says it's in } \\
\text { reverse order, so if you wanted to know } \\
\text { what's coming up that would most likely be } \\
\text { accessible on this as well.' (Pat, BPUJC, } \\
\text { Transcript) }\end{array}$ \\
\hline
\end{tabular}


Mental models and social media personas: A case of amateur palaeontologists

Table 4: Minor coded themes across three types of collected data

\begin{tabular}{|c|c|c|c|}
\hline Theme & $\begin{array}{l}\text { Coded } \\
\text { Instances }\end{array}$ & $\begin{array}{l}\text { Operational } \\
\text { Definition }\end{array}$ & $\begin{array}{l}\text { Coded } \\
\text { Example }\end{array}$ \\
\hline Platform & $35(8 \%)$ & $\begin{array}{l}\text { The tools, } \\
\text { media, and } \\
\text { working } \\
\text { environment }\end{array}$ & $\begin{array}{l}\text { 'hands on type of video to gain perspective, } \\
\text { chat option.' (Reagan, GTFO6, Survey } \\
\text { Q25) }\end{array}$ \\
\hline Membership & $25(5 \%)$ & $\begin{array}{l}\text { Becoming part } \\
\text { of a group }\end{array}$ & $\begin{array}{l}\text { 'People who have similar interests...groups } \\
\text { who use the site...generated by similar } \\
\text { interests.' (Riley, HPUF2, Survey Q23) }\end{array}$ \\
\hline $\begin{array}{l}\text { Frame(s) of } \\
\text { Reference }\end{array}$ & $19(4 \%)$ & $\begin{array}{l}\text { A personal, } \\
\text { philosophical, or } \\
\text { previous } \\
\text { orientation to } \\
\text { participation and } \\
\text { contribution }\end{array}$ & $\begin{array}{l}* * \text { Dependent on Frame, e.g. Frame of } \\
\text { Reference-Continuum of Expertise: } \\
\text { 'I come from a very highly technical, } \\
\text { boring, mind-numbing business and to me } \\
\text { the fossil... an amateur palaeontologist, we } \\
\text { do it for fun. We don't want this to be } \\
\text { difficult; we want it to be entertaining and } \\
\text { fun.' (Alex Z9720 Transcript) }\end{array}$ \\
\hline Tension & $13(3 \%)$ & $\begin{array}{l}\text { A disconnect in } \\
\text { the person's } \\
\text { views of the task } \\
\text { and their } \\
\text { persona or } \\
\text { mental model }\end{array}$ & $\begin{array}{l}\text { 'Ok, that's easy then because all of these } \\
\text { just come right back, but you need to see } \\
\text { the definitions.' (Kerry, O1O60, Transcript) }\end{array}$ \\
\hline $\begin{array}{l}\text { Challenged } \\
\text { by the Task }\end{array}$ & $11(2 \%)$ & $\begin{array}{l}\text { Expression of } \\
\text { frustration, etc. } \\
\text { concerning the } \\
\text { activity }\end{array}$ & $\begin{array}{l}\text { 'This is hard!' (Parker, CO2GG, } \\
\text { Transcript) }\end{array}$ \\
\hline $\begin{array}{l}\text { Interesting } \\
\text { Comment }\end{array}$ & $8(2 \%)$ & $\begin{array}{l}\text { A remark that } \\
\text { does not fit with } \\
\text { other codes, but } \\
\text { is unique } \\
\text { enough in some } \\
\text { capacity that it } \\
\text { bears marking }\end{array}$ & $\begin{array}{l}\text { 'And comment is usually this is a place on } \\
\text { the website that people will make the } \\
\text { comments like, 'I don't like this website,' } \\
\text { or whatever, so this is a good one; comment } \\
\text { is really important on a website I think. } \\
\text { They will tell me exactly this website didn't } \\
\text { have enough information for the people.' } \\
\text { (Parker, CO2GG, Transcript) }\end{array}$ \\
\hline $\begin{array}{l}\text { View } \\
\text { Photo }\end{array}$ & $7(2 \%)$ & $\begin{array}{l}\text { Viewing images } \\
\text { of field } \\
\text { experiences or } \\
\text { fossils }\end{array}$ & $\begin{array}{l}\text { 'Excellent illustrations and photos would be } \\
\text { expected.' (Riley, HPUF2, Survey Q17) }\end{array}$ \\
\hline
\end{tabular}


Figure 1 Frequency of social media convention use by type of activity for social palaeontology and by social media persona. Asterisks (*) denote instances in which no conventions were used by participants.

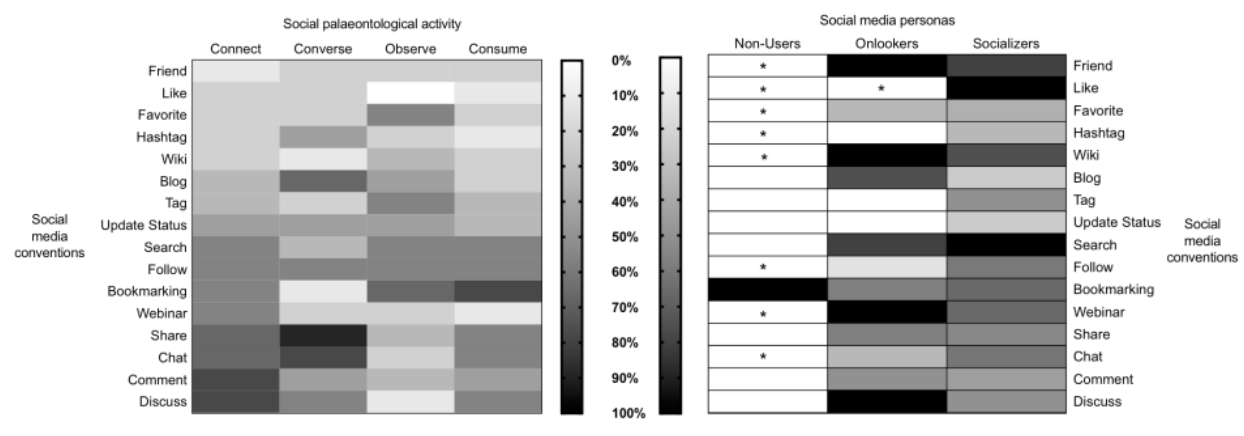

Figure 2 The structures of mental models for each type of activity

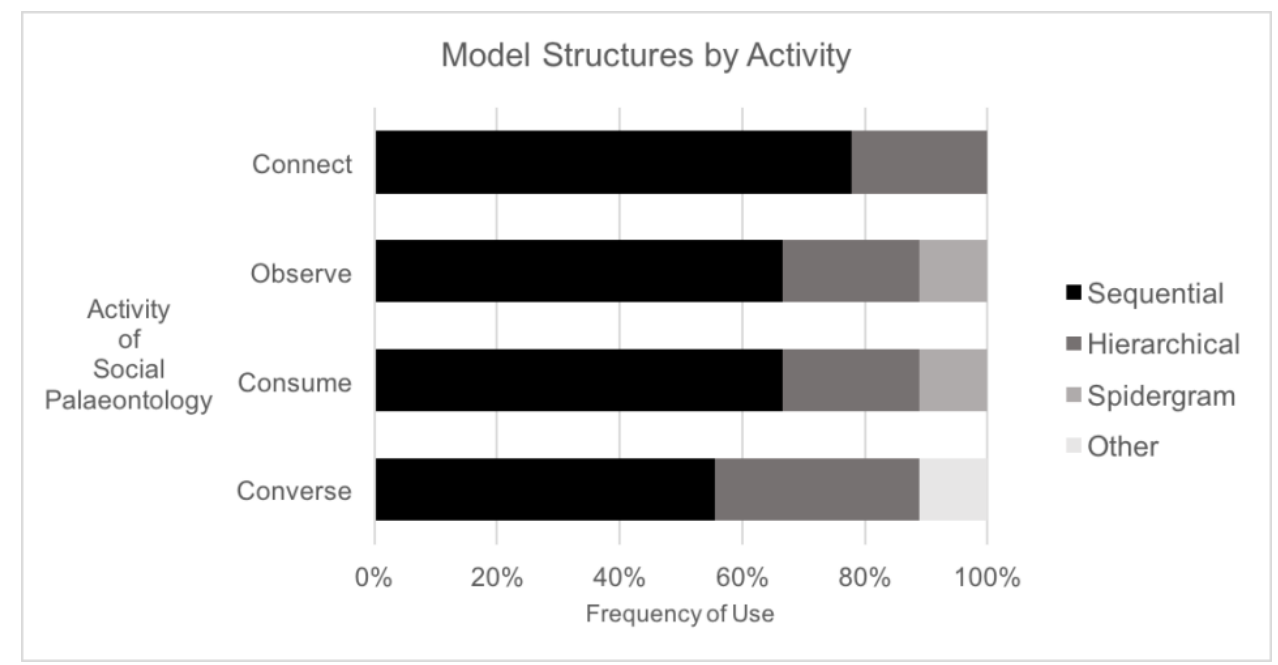


Mental models and social media personas: A case of amateur palaeontologists

Figure 3 Example of sequential (A) and hierarchical (B) mental model structures
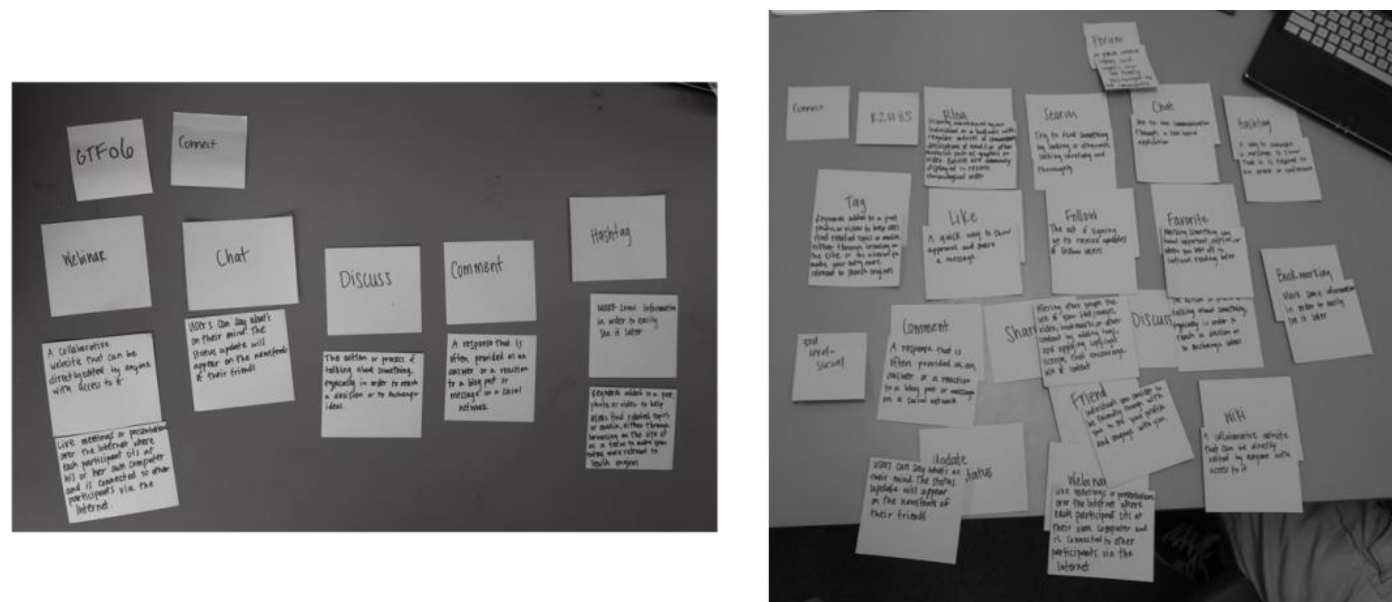

A: Sequential mental model (described by the participant as reading left to right)

B: Hierarchical mental model (described by the participant as reading top to bottom)

Figure 4 Structural breakdown of major and minor themes

Major themes

Minor themes
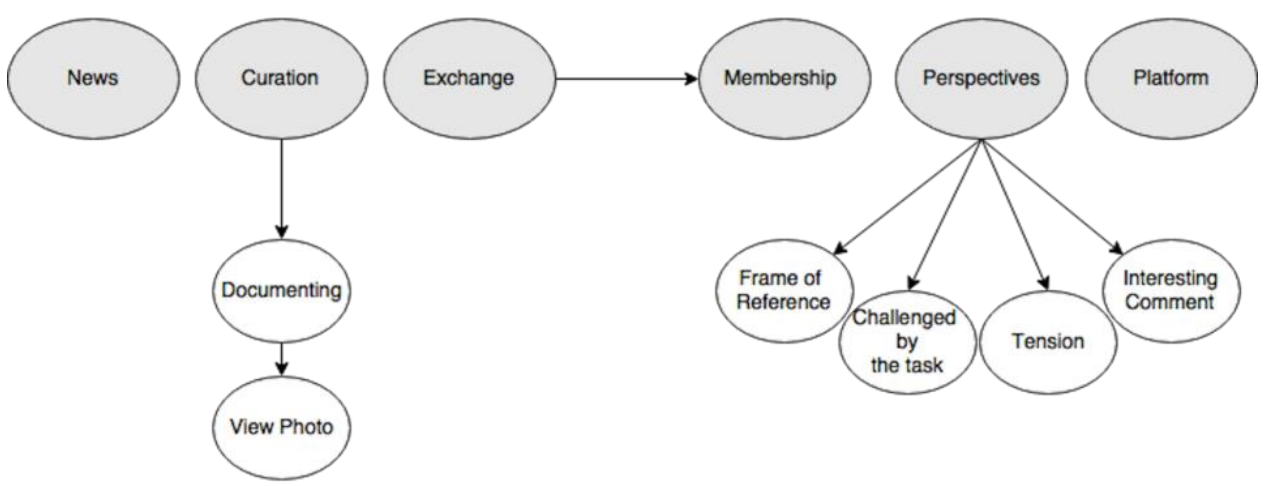
Figure 5 Frequency of coded themes for each type of activity

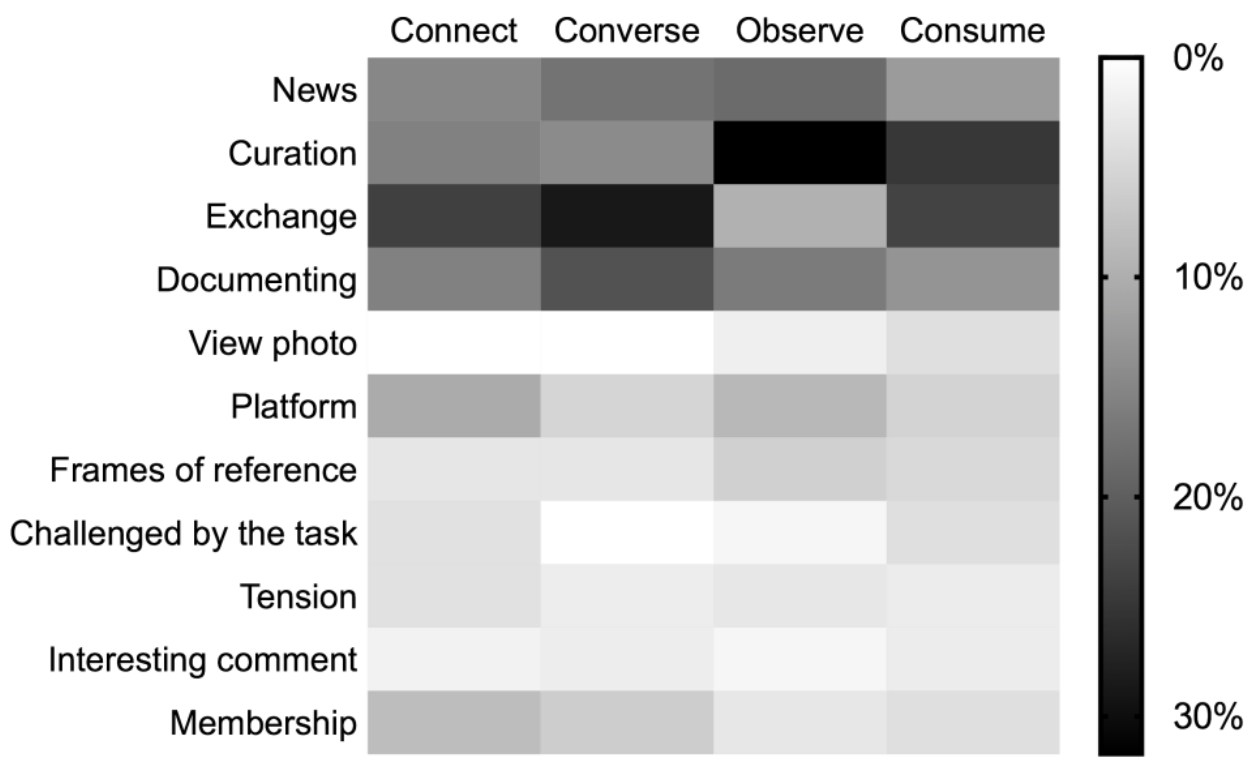

Figure 6 The structures of mental models for each social media persona

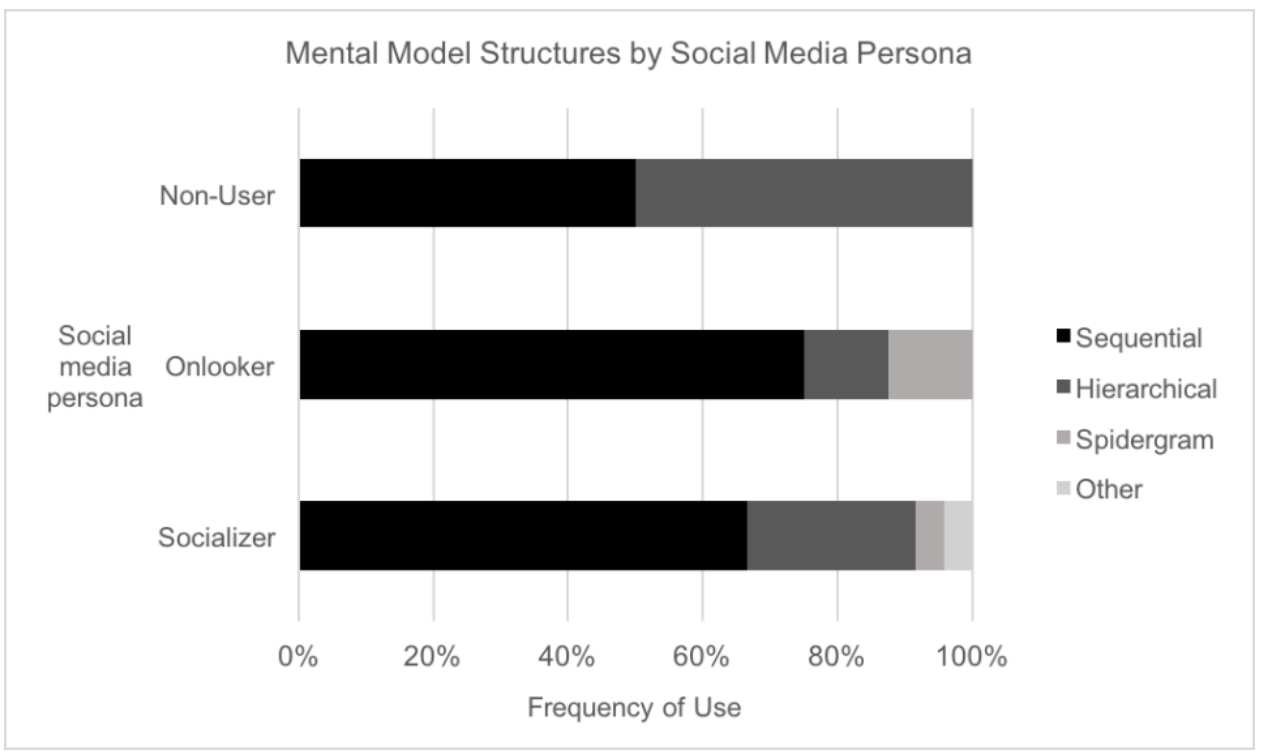


Mental models and social media personas: A case of amateur palaeontologists

\section{Appendix A}

Social Media Use and Typology Questions

Do you use social media (i.e. Twitter, Facebook, Instagram)?

Yes

No

Which best describes your use of social media?

Almost Never

Every few days

Daily

Multiple Times Daily

I'm always online

Which social media networks do you use? Check all that you use/

Facebook

YouTube

Twitter

Pinterest

LinkedIn

Instagram

Blogs

Other (Please Name)

Which tools do you use to access social media? Check all that you use.

Computer

Android Phone

iPhone

iPad

Other tablet computer 
Which of the following sentences best describes your personal use of social media? Choose the Best.

'I don't check social media because I don't find it worthwhile.'

'I check social media, but I don't post a lot of things.'

'I use social media to exchange information and check in with people.'

'I use social media to post about my day, I check in with others. I'm always keeping up.'

'I don't want to miss anything, so I'm always checking my social media.' 